\title{
Heavy Metals
}

\author{
Kristine Edgar Danielyan* and Samvel Grigoriy Chailyan \\ H Bunitain Institute of Biochemistry, National Academy of Science of Armenia, Armenia
}

*Corresponding author: Kristine Edgar Danielyan, H Bunitain Institute of Biochemistry, National Academy of Science of Republic

of Armenia, Armenia

\section{ARTICLE INFO}

Received: 幽 October 01, 2019

Published: 幽 October 09, 2019

Citation: Kristine Edgar D, Samvel Grigoriy C. Heavy Metals. Biomed J Sci \& Tech Res 21(5)-2019. BJSTR. MS.ID.003659.

Keywords: Heavy Metals; Cancer; Free Radicals; Xanthine Oxidoreductase

\begin{abstract}
World Health Organization determined 13 heavy metals as the health harming compounds; arsenic, cadmium, cobalt, chromium, copper, mercury, manganese, nickel, lead, tin and titanium, initiating and exacerbating the pathologies. Some intoxication are due to the environmental pollutions, involves large populations and often not instantly might be recognized. Fast overview of the short clinical manifestations of such intoxications, epidemiological intoxication history facts as well as the possible new mechanism of the treatment might be beneficial for the readers.
\end{abstract}

Abbreviations: WHO: World Health Organization; IGF: Inter Governmental Forum; TG: Terra Graphics Environmental Engineering; CDC: Centers for Disease Control and Prevention; CNS: Central Nervous System; XO: Xanthine Oxidase; BBB: Blood-Brain Barrier; MAP: Mitogen-Activated Protein; ROIs: Reactive Oxygen Intermediates

\section{Mini Review}

World Health Organization (WHO) accounted 13 heavy metals, which have a significant impact on the environment as well as on human health. The list of these metals includes arsenic, cadmium, cobalt, chromium, copper, mercury, manganese, nickel, lead, tin, and titanium [1]. Sources of heavy metals vary, but human exposure is largely attributed to mining and industrial operations, including metal refineries, petrochemical production, power plants, and electronics manufacturing. Contamination can also occur from diffuse sources, such as aging metal pipes, food contamination, sewage discharge, and leaching from landfills [2]. The 2016 meeting of the Intergovernmental Forum on Mining, Minerals, Metals, and Sustainable Development (IGF) concluded with its 62 member countries about the need for stronger legal frameworks that protect workers from mining-related pollution [3]. The heavy metals intoxication due to the industrial lashing of waste materials is more pronounced in the developing countries. For instance, In Zamfara State, Nigeria, an epidemic of lead poisoning from artisanal mining led to the deaths of about 163 people between March and June 2010, including 111 children under five years of age [4].

Terra Graphics Environmental Engineering (TG), World Health Organization (WHO), and Centers for Disease Control and Prevention (CDC), reported that approximately 400 children $<$ five years old have been killed from the outbreak and thousands of people affected, including $>2000$ children left with permanent disabilities [5-7] Dooyema, et al. [7] measured the concentrations of soil $\mathrm{Pb}$ and soil $\mathrm{Hg}$ which showed $>100,000 \mathrm{ppm}$ and about 4600 $\mathrm{ppm}$ for $\mathrm{Pb}$ and $\mathrm{Hg}$, respectively. The study found that surviving children<five years of age had blood $\mathrm{Pb}$ levels (BLL) of about $370 \mathrm{ug} / \mathrm{dL}$ which is above the CDC recommended BLL of $5 \mathrm{ug} / \mathrm{dL}$ [8]. It is necessarily to mention, the developing brain of children are very susceptible to the impact of the heavy metals. Heavy metals easily penetrate trough the hemato encephalic barriers and impair the physiological activity of the neuro-glial environment.

The developing brain is vulnerable to injury from toxic metals that interfere with the critical developmental processes, i.e., cellular proliferation, migration, differentiation, synaptogenesis myelination and apoptosis in the central nervous system (CNS) [9]. The limited capacity of the developing CNS to compensate for the cell loss and the disruptions in neural networking results in compromised neuronal functions [10] and increased risk of neurodegeneration [11]. Heavy metals including arsenic (As), cadmium (Cd), and lead $(\mathrm{Pb})$ have received attention as both environmental contaminants and potential neurotoxicological hazards [12]. Exposure to the metals in utero and in infancy is associated with risk of im- 
paired cognitive development [13], subclinical brain dysfunction [14] and behavioral anomalies [15]. Heavy ( $\mathrm{Cd}, \mathrm{Hg}, \mathrm{Pb}$, and $\mathrm{As}$ ) and transition metals ( $\mathrm{Fe}, \mathrm{Cu}, \mathrm{Co}$, and $\mathrm{Cr}$ ), acting as powerful oxidative stress inducers and are responsible for various forms of nephropathy, as well as for some types of cancers [16].

Our laboratory investigates the one of the main initiators of the free radical's formation Xanthine Oxidoreductase, which is responsible for the purine catabolism final steps and standing in the mentioned pathway as the regulative enzymes. Under normal circumstances, most amount of this enzyme exists in the form of NAD-dependent cytosolic dehydrogenase (XDH). However, in pathological conditions Xanthine Oxidase (XO) might be formed due to the limited proteolysis [17]. XO as well as the XDH are also responsible for the hydroxylation of a wide variety pyrimidine, pterin, and aldehyde substrates (EC: 1.17.1.4). We have proceeded the investigations related with the impact of the heavy metals on the activity of XOR in the rat's brain. The published results are evidencing, heavy metals are elevating XOR activity and, consequently, elevating the formation of free radicals. $\mathrm{Cd}^{2+}$ elevated the activity of the XOR in comparison with the control 0,5338 $\pm 0,1542$ vs $0,6488 \pm 0,3635 . \mathrm{Cr}^{6+}$ ions elevated the activity of XOR until 2,3996 $\pm 0,3541$ ( $\mathrm{p \# <0.05}$ ), $\mathrm{Pb}^{2+}$ - until 0,9492 $\pm 0,3880$ and $\mathrm{Hg}^{2+}$ - until 1,1604 $\pm 0,6918$ [17]. Also, in our previous investigations, we have shown, that pyridoxine or vitamin B6 is able to diminish the activity of XOR, in the low concentration $(0.05 \mathrm{mg} / \mathrm{ml})$ [18]. Pyridoxine was able mostly to diminish the activity of the XOR in the presence of the heavy metals. The impact of the ions of the $\mathrm{Cd}^{2+}$ were switching the value until 0,8522 $\pm 0,3461$, for $\mathrm{Cr}^{6+}$ until 0,1098 $\pm 0,1098$; for $\mathrm{Pb}^{2+}$ $0,0130 \pm 7,9066 \mathrm{e}-3$ and for $\mathrm{Hg}^{2}+-0,6791 \pm 0,3572$ ( $\mathrm{p} \#<0,037489$ between the activation of $\mathrm{Pb}^{2+}$ and that suppression under the impact of the pyridoxine; $\mathrm{p \# <}<0.05$ between the activation of $\mathrm{Cr}^{6+}$ and that suppression under the impact of the pyridoxine) in comparison with the controls, where there were added the substrate and [17] Thus, B6 is suggested for the use along with the other medications to cure heavy metals intoxication due to the inhibition of free radicals' formation (Figure 1).

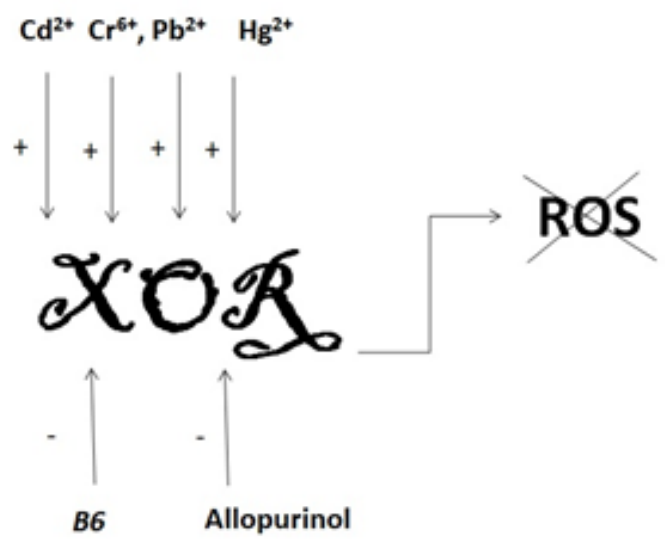

Figure 1: Reversed by B6 impact of heavy metals on XOR activity.

\section{$\mathrm{Pb}$}

The symptoms of acute lead poisoning are headache, irritability, abdominal pain and various symptoms related to the nervous system. Lead encephalopathy is characterized by sleeplessness and restlessness. Children may be affected by behavioral disturbances, learning and concentration difficulties. In severe cases of lead encephalopathy, the affected person may suffer from acute psychosis, confusion and reduced consciousness. People who have been exposed to lead for a long time may suffer from memory deterioration, prolonged reaction time and reduced ability to understand. Individuals with average blood lead levels under $3 \mu \mathrm{mol} / \mathrm{l}$ may show signs of peripheral nerve symptoms with reduced nerve conduction velocity and reduced dermal sensibility. If the neuropathy is severe the lesion may be permanent. In less serious cases, the most obvious sign of lead poisoning is disturbance of hemoglobin synthesis, and long-term lead exposure may lead to anemia [19]. Acute exposure to lead is known to cause proximal renal tubular damage [19]. IARC classified lead as a 'possible human carcinogen' based on enough animal data and insufficient human data in 1987. Since then a few studies have been published, the overall evidence for lead as a carcinogen being only weak, the most likely candidates are lung cancer, stomach cancer and gliomas [20].

Studies with single metal exposure have demonstrated that As, $\mathrm{Cd}$, or Pb infiltrate the immature blood-brain barrier (BBB) and accumulate in developing brain [21]. $\mathrm{Pb}$ uptake through the BBB disrupts $\mathrm{Ca} 2 \mathrm{p}$ transport mechanism [22] and promotes activation of mitogen-activated protein (MAP) kinases in apoptotic glial cells [23]. The sequestration of $\mathrm{Pb}$ at the level of the choroid plexus undermines brain growth and affects learning and cognitive functions of CNS [22], especially in children. Combination of 1-month pre-exposure of $\mathrm{HgC}_{12}$ before $\mathrm{MI}$ changed the endothelial generation of oxidative stress induced by mercury exposure from NADPH oxidase pathway to XO (xanthine oxidase)-dependent ROS production [24]. It has been suggested that reactive oxygen intermediates (ROIs) may have a role in the genotoxic effects of lead $\left(\mathrm{Pb}^{2+}\right)$ and mercury $\left(\mathrm{Hg}^{2+}\right)$.

$\mathrm{Pb}^{2+}$ and $\mathrm{Hg}^{2+}(0.1-1 \mu \mathrm{M})$ had no effect on the activities of partially purified catalase, glutathione peroxidase, or glutathione reductase, important enzymes involved with antioxidant defense, but these metals stimulated the activities of copper-zinc superoxide dismutase (CuZn-SOD) and xanthine oxidase (XO). Allopurinol $(50 \mu \mathrm{M})$, a specific inhibitor of xanthine oxidase, inhibited the induction of $\mathrm{H}_{2} \mathrm{O}_{2}$ by $\mathrm{Pb}^{2+}(0.8-1 \mu \mathrm{M})$ and $\mathrm{Hg}^{2+}(1 \mu \mathrm{M})$ and inhibited $\mathrm{Pb}^{2+}$ - and $\mathrm{Hg}^{2+}$-induced mutagenesis. These results demonstrate that $\mathrm{Pb}^{2+}$ and $\mathrm{Hg}^{2+}$ disrupt the redox status of AS52 cells by enhancing the activities of CuZn-SOD and XO [25].

\section{Cd}

In vivo and in vitro studies have revealed that acute or chronic $\mathrm{Cd}$ exposure enhances oxidative stress in astrocytes and 
accumulates reactive oxygen species (ROS) that induces astrocytic death [26]. Perinatal exposure to Cd induces anxiety [27,28] and reduces learning ability of offspring [28]. Cadmium is a toxic metal with negative effects on health [29]. Previous studies have confirmed the pathogenic role of cadmium exposure in renal damage, bone destruction and cancer [30]. To determine whether $\mathrm{CdB}$ in Chinese adults is associated with serum UA (Uric Acid) and hyperuricemia, 2996 participants from the cross-sectional SPECTChina study were recruited. A positive relationship between serum $\mathrm{UA}$ and $\mathrm{CdB}$ was found in Chinese men after adjusting for the estimated glomerular filtration rate (eGFR), current smoking status, diabetes, dyslipidemia, hypertension and body mass index and in participants with eGFR $>60 \mathrm{~mL} / \mathrm{min}$ per $1.73 \mathrm{~m}^{2}$. Further, the odds ratio of hyperuricemia increased with increasing $\mathrm{CdB}$ quartiles ( $\mathrm{P}$ for trend $<0.05$ ) in men. In conclusion, $\mathrm{CdB}$ was positively related to the serum UA level [31]. These data clearly evidencing about the activation of XOR and Cd intoxication process of the organism. Inhalation of cadmium fumes or particles can be life threatening, and although acute pulmonary effects and deaths are uncommon, sporadic cases still occur [32,33]. Cadmium exposure may cause kidney damage [34]. IARC has classified cadmium as a human carcinogen (group I) based on enough evidence in both humans and experimental animals [35]. Cadmium has been associated with prostate cancer, but both positive and negative studies have been published. Early data indicated an association between cadmium exposure and kidney cancer [36].

\section{As}

Chronic exposure to As, even at a sub micromolar concentration, promotes oxidative stress [37] and induces neuroglial damage in human brain [38]. Intoxication with As presents deficits in spontaneous locomotor activity (SLA) and alterations in learningmemory task during postnatal development [39]. Inorganic arsenic is acutely toxic and intake of large quantities leads to gastrointestinal symptoms, severe disturbances of the cardiovascular and central nervous systems, and eventually death. In survivors, bone marrow depression, hemolysis, hepatomegaly, melanosis, polyneuropathy and encephalopathy may be observed. Ingestion of inorganic arsenic may induce peripheral vascular disease, which in its extreme form leads to gangrenous changes (black foot disease, only reported in Taiwan). Populations exposed to arsenic via drinking water show excess risk of mortality from lung, bladder and kidney cancer, the risk increasing with increasing exposure. There is also an increased risk of skin cancer and other skin lesions, such as hyperkeratosis and pigmentation changes [40].

\section{$\mathrm{Hg}$}

Acute mercury exposure may give rise to lung damage. Chronic poisoning is characterized by neurological and psychological symptoms, such as tremor, changes in personality, restlessness, anxiety, sleep disturbance and depression. The symptoms are reversible after cessation of exposure. Because of the bloodbrain barrier there is no central nervous involvement related to inorganic mercury exposure. Metallic mercury may cause kidney damage, which is reversible after exposure has stopped. It has also been possible to detect proteinuria at relatively low levels of occupational exposure. Metallic mercury is an allergen, which may cause contact eczema, and mercury from amalgam fillings may give rise to oral lichen. It has been feared that mercury in amalgam may cause a variety of symptoms. This so-called 'amalgam disease' is, however, controversial, and although some authors claim proof of symptom relief after removal of dental amalgam fillings [41], there is no scientific evidence of this [42].

Organic mercury Methyl mercury poisoning has a latency of 1 month or longer after acute exposure, and the main symptoms relate to nervous system damage [43]. The earliest symptoms are paresthesia and numbness in the hands and feet. Later, coordination difficulties and concentric constriction of the visual field may develop as well as auditory symptoms. High doses may lead to death, usually 2-4 weeks after onset of symptoms. The Minamata catastrophe in Japan in the 1950s was caused by methyl mercury poisoning from fish contaminated by mercury discharges to the surrounding sea. In the early 1970s, more than 10,000 persons in Iraq were poisoned by eating bread baked from mercury-polluted grain, and several thousand people died because of the poisoning. However, the general population does not face significant health risks from methyl mercury exposure except for certain groups with high fish consumption. A high dietary intake of mercury from consumption of fish has been hypothesized to increase the risk of coronary heart disease [44].

Early recognition of the possible environmental pollutions and organism intoxication is the import environmental, political, health conserving and protecting primer duty for any and especially for the developing countries.

\section{Acknowledgment}

The work was made possible because of ANSEF biochem-4414 award (PI: Kristine Danielyan). The work was supported also by the basic funding from the National Academy of Science of Armenia as well as the grant from the Science Committee of Ministry of Education and Science of Armenia (PI: Samvel G. Chailyan18T-1F089).

\section{References}

1. (2011) WHO, Training Package for the Health Sector: Adverse Health Effects of Heavy Metals in Children? World Health Organization.

2. (2008) UNEP-CEP, Heavy Metals.

3. Crawford A (2015) The Mining Policy Framework: Assessing the implementation readiness of member states of the Intergovernmental Forum on Mining, Minerals, Metals and Sustainable Development. International Institute for Sustainable Development.

4. Carrigan PE, Hentz JG, Gordon G, Morgan JL, Raimondo M, et al. (2007) Distinctive heavy metal composition of pancreatic juice in patients with pancreatic carcinoma. Cancer Epidemiol Biomarkers Prev 16(12): 26562663.

5. Lo YC, Dooyema CA, Neri ADJ, Jefferies T, Medina Marino A, et al. (2012) Childhood lead poisoning associated with gold ore processing: a village- 
level investigation-Zamfara State, Nigeria, October-November 2010. Environ Health Perspect 120(10): 1450-1455.

6. Von Lindern IH, Von Braun MC, Tirima S, Bartrem C Zamfara (2012) Nigeria Lead Poisoning Epidemic Emergency Environmental Response, May 2010-March 2011, Final Report to the United Nations Childrens Fund (UNICEF) 2011 UNICEF Programme cooperation Agreement: YW303(01).

7. Dooyema CA, Neri A, Lo YC, Durant J, Dargan PI, et al. (2012) Outbreak of fatal childhood lead poisoning related to artisanal gold mining in northwestern Nigeria, 2010. Environ Health Perspect 120(4): 601-607.

8. (2012) CDC (Centers for Disease Control and Prevention) Response to the Advisory Committee on Childhood Lead Poisoning Prevention Report, Low Level Lead Exposure Harms Children: A Renewed Call for Primary Prevention. CDC; Atlanta, GA, USA.

9. Rice D, Barone S (2000) Critical periods of vulnerability for the developing nervous system: evidence from humans and animal models. Environ Health Perspect 108(Suppl3): 511-533.

10. Bayer SA (1989) Cellular aspects of brain development. Neurotoxicology 10(3): 307-320.

11. Grandjean P, Landrigan PJ (2006) Developmental neurotoxicity of industrial chemicals. Lancet 368(9553): 2167-2178.

12. Jadhav SH, Sarkar SN, Patil RD, Tripathi HC (2007) Effects of subchronic exposure via drinking water to a mixture of eight water contaminating metals: a biochemical and histopathological study in male rats. Arch Environ Contam Toxicol 53(4): 667-677.

13. Hu H (2000) Exposure to metals. Prim Care 27(4): 983-996.

14. Lanphear BP, Hornung R, Khoury J, Yolton K, Baghurst P, et al. (2005) Low-level environmental lead exposure and children's intellectual function: an international pooled analysis. Environ Health Perspect 113(7): 894-899.

15. Wright RO, Amarasiriwardena C, Woolf AD, Jim R, Bellinger DC (2006) Neuropsychological correlates of hair arsenicmanganese, and cadmium levels in school-age children residing near a hazardous waste site. Neurotoxicology 27(2): 210-216.

16. Valko M, Rhodes, CJ, Moncol J, Izakovic M (2006) Free radicals, metals and antioxidants in oxidative. Chemico-Biological Interactions 160(1): $1-40$.

17. Danielyan KE, Babayan LA, Chailyan SG (2019) The Impact of the Heavy Metals on the Activity of the Xanthine Oxidoreductase Activity. Appl Clin Pharmacol Toxicol 3: 123.

18. Aganyants H, Abrahamyan R, Chailyan SG, Danielyan KE (2014) New Highlights in the Regulation of Cells Proliferation. Neuroscience and Biomedical Engineering 2(2): 81-86.

19. (1995) WHO, Lead. Environmental Health Criteria, World Health Organization, Geneva, Switzerland pp. 165.

20. Steenland K, Boffetta P (2000) Lead and cancer in humans: where are we now? Am J Ind Med 38(3): 295-299.

21. Xi S, Jin Y, Lv X, Sun G (2010) Distribution and speciation of arsenic by transplacental and early life exposure to inorganic arsenic in offspring rats. Biol Trace Elem Res 134(1): 84-97.

22. Marchetti C (2003) Molecular targets of lead in brain neurotoxicity. Neurotox Res 5(3): 221-236.

23. Posser T, De Aguiar CB, Garcez RC, Rossi FM, Oliveira CS, et al. (2007) Exposure of $\mathrm{C} 6$ glioma cells to $\mathrm{Pb}(\mathrm{II})$ increases the phosphorylation of p38(MAPK) and JNK1/2 but not of ERK1/2. Arch Toxicol 81(6): 407414.

24. Faria TO, Simões MR, Vassallo DV, Forechi L, Almenara CCP, et al. (2018) Xanthine Oxidase Activation Modulates the Endothelial (Vascular) Dysfunction Related to $\mathrm{HgCl} 2$ Exposure Plus Myocardial Infarction in Rats. Cardiovasc Toxicol 18(2): 161-174.
25. Ariza ME, Bijur GN, Williams MV (1998) Lead and mercury mutagenesis: role of $\mathrm{H} 2 \mathrm{O} 2$, superoxide dismutase, and xanthine oxidase. Environ Mol Mutagen 31(4): 352-361.

26. Yang CS, Tzou BC, Liu YP, Tsai MJ, Shyue SK, et al. (2008) Inhibition of cadmium-induced oxidative injury in rat primary astrocytes by the addition of antioxidants and the reduction of intracellular calcium. J Cell Biochem 103(3): 825-834.

27. Minetti A, Reale CA (2006) Sensorimotor developmental delays and lower anxiety in rats prenatally exposed to cadmium. J Appl Toxicol 26(1): 35-41.

28. Ishitobi H, Mori K, Yoshida K, Watanabe C (2007) Effects of perinatal exposure to low-dose cadmium on thyroid hormone-related and sex hormone receptor gene expressions in brain of offspring. Neurotoxicology 28(4): 790-797.

29. Jarup L, Akesson A (2009) Current status of cadmium as an environmental health problem. Toxicology and applied pharmacology 238(3): 201-208.

30. Musacchio Eea, Perisinotto E, Sartori L, Veronese N, Punzi L, et al. (2016) Hyperuricemia, Cardiovascular Profile, and Comorbidity in Older Men and Women. Rejuvenation research 20(1): 42-49.

31. Sun H, Wang N, Chen C, Nie X, Han B, et al. (2017) Cadmium exposure and its association with serum uric acid and hyperuricemia. Sci Rep 7(1): 550 .

32. Seidal K, Jorgensen N, Elinder C, Sjogren B, Vahter M (1993) Fatal cadmium-induced pneumonitis. Scand J Work Environ Health 19(6): 429-431.

33. Barbee JJY, Prince TS (1999) Acute respiratory distress syndrome in a welder exposed to metal fumes. South Med J 92(5): 510-512.

34.(1992) Organization GWH, WHO. Cadmium. Environmental Health Criteria pp. 134

35. (1993) IARC, Cadmium and cadmium compounds. In: Beryllium C, Mercury and Exposure in the Glass Manufacturing Industry. IARC Monographs on the Evaluation of Carcinogenic Risks to Humans. Lyon: International Agency for Research on Cancer.

36. Kolonel LN (1976) Association of cadmium with renal cancer. Cancer 37(4): 1782-1787.

37. Garcia Chavez E, Jimenez I, Segura B, Del Razo LM (2006) Lipid oxidative damage and distribution of inorganic arsenic and its metabolites in the rat nervous system after arsenite exposure: influence of alpha tocopherol supplementation. Neurotoxicology 27(6): 1024-1031.

38. Jin Y, Sun G, Li X, Li G, Lu C, et al. (2004) Study on the toxic effects induced by different arsenicals in primary cultured rat astroglia. Toxicol Appl Pharmacol 196(3): 396-403.

39. Rodriguez VM, Dufour L, Carrizales L, Diaz Barriga F, Jimenez Capdeville ME (1998) Effects of oral exposure to mining waste on in vivo dopamine release from rat striatum. Environ Health Perspect 106(8): 487-491.

40. (2001) WHO, Arsenic and Arsenic Compounds. Environmental Health Criteria pp. 224

41. Lindh U, Hudecek R, Danersund A, Eriksson S, Lindvall A (2002) Removal of dental amalgam and other metal alloys supported by antioxidant therapy alleviates symptoms and improves quality of life in patients with amalgam-associated ill health. Neuroendocrinol Lett 23(5-6): 459-482.

42. Langworth S, Bjorkman L, Elinder CG, Jarup L, Savlin P (2002) Multidisciplinary examination of patients with illness attributed to dental fillings. J Oral Rehabil 29(8): 705-713.

43. Weiss B, Clarkson TW, Simon W (2002) Silent latency periods in methylmercury poisoning and in neurodegenerative disease. Environ Health Perspect 110(Suppl 5): 851-854.

44. Salonen JT, Seppanen K, Nyyssonen K, Korpela H, Kauhanen J, et al. (1995) Intake of mercury from fish, lipid peroxidation, and the risk of myocardial infarction and coronary, cardiovascular, and any death in eastern Finnish men. Circulation 91(3): 645-655. 


\section{ISSN: 2574-1241}

DOI: 10.26717/BJSTR.2019.21.003659

Kristine Edgar Danielyan. Biomed J Sci \& Tech Res

(c) (i) This work is licensed under Creative

Submission Link: https://biomedres.us/submit-manuscript.php

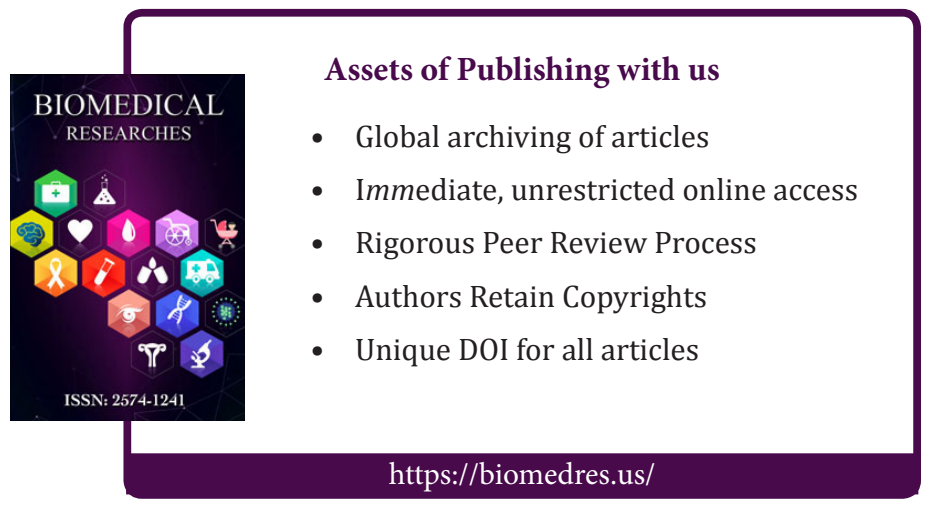

